\title{
Crop modeling: a tool for agricultural research
}

\begin{abstract}
The Earth's natural resources are finite, whereas the amount of people that the land ought to support continues to grow quickly. This creates a significant downside for agricultural production and productivity ought to be hyperbolic to satisfy quickly growing demands whereas natural resources ought to be protected. New agricultural analysis is needed to supply knowledge to the farmers, policy and various decision makers on their accomplish property agriculture over the widely diverged variations in climate around the world. The deployment of crop models throughout this direction in analysis is being impressed, at present time. A model can be a schematic illustration of the conception of a system or associate act of mimicry or a set of equations that represents the behaviour of a system. Thus, a model is defined as "an illustration of degree object, system or set up in some sort apart from that of the entity itself". Its purpose is usually to assist in explaining, understanding or up performance of a system.
\end{abstract}

Keywords: crop modeling, decision support, agricultural tool, yield and its attributes
Volume 6 Issue 4 - 2018

\author{
Zaman A, Sagar Maitra \\ School of Agriculture, Centurion University of Technology and \\ Management, India
}

Correspondence: Zaman A, School of Agriculture, Centurion University of Management \& Technology, Paralakhemundi-76I 2II, Odisha, India, Email profazaman@gmail.com

Received: May 15, 2018 | Published: July 19, 2018

\section{Introduction}

Crop modeling as degree advance tool in agriculture may be a complicated development that's rough to be used as a results, it provided a comprehensive narration of an objective condition, it's a robust tool to provide a clear, useful illustration as an area of reality, that captures the essential components and mechanisms of that system and even further hard, once the fashionable systems restricted in management problems associated with environmental ecology. ${ }^{1}$ The DSS web is totally computerized that permits the users to incorporate all technical information contained in crop growth models with economic concerns and environmental impact evaluations those are presently offered. DSSAT ${ }^{2}$ is also a rattling example of a management tool that allowed individual farmers to match the biological demand of a crop to the physical characteristics of the land to induce given objectives within the agricultural analysis sector, modeling may be a novel discipline and basic information on the applying of those models in analysis isn't just on the market. Modeling is that the use of equations or sets of equations to represent the behaviour of a system in growth and development of agricultural crops and in purpose of truth. Hence, crop models are computerized programmes that mimic the enlargement and development of crops as per governmental departments of various counties, as reported first widely in 2007. Model simulates or imitates the behaviour of a true crop by foreseeing and predicting the economic yield from its components, like leaves, roots, stems and grains. Thus, a crop growth simulation model predicts the last word state of crop production or biomass yield and additionally to its content quantitative data associated with major processes that concerned within the growth and development of the crop.

Hence, throughout this back drop, the current review work was applied to understand the crop modeling as degree advance tool in trendy agriculture.

\section{Review of literature}

A system may be a restricted a local reality that contains interacting components and a model may be a simplified illustration of such systems. ${ }^{3}$ The indices helps North yank nation to grasp the globe around North yank nation. Specifically, a crop model is expressed as a topic in terms of amount for prognostication, the enlargement and productivity of a crop per unit space, below a given set of genotype selections and in similar set of environmental variables. ${ }^{4}$ Model of crop simulation generally called as CSM measures defectively the representations of crop growth developed by laptop or computer system and furthermore as yield, a simulated and expressed through mathematical equations as functions of soil scenario, atmospheric condition and crop management practices. ${ }^{5}$ Empirical models has been described and as has been referred here, additionally to as descriptive or regression models and those square measure direct descriptions of empiric information that works in response of maize yield to utterly totally different rates of fertilizer and driving variables. Crop growth models are instructive models and find to elucidate the functioning of crops as a full ${ }^{6}$ by simulating or imitating the performance of crop in reality in terms of growth and yield attributes ${ }^{7}$ wherein they're doing not entirely predict final biomass or harvestable yield, however in addition it contained data regarding major processes involved inside the expansion and development of a plant which they typically in addition offer data on externalities, like erosion or N-leaching and various physical properties of the soil. Crop growth models are utilized in varied studies to help farmers around the world creating in day-to-day higher noises, as associate example, to analysis the results of management decisions like sowing time, plant population density, irrigation regime (timing, frequency) and plant food applications in many conditions on semi-permanent mean yield and yield probability ${ }^{6}$ of the crop.

\section{Analysis of results}

\section{Leaf area index}

APSIM-Maize model simulated the utmost Leaf Area Index well, with higher accuracy for the maize. ${ }^{8}$ Gungula et al., ${ }^{9}$ similarly also discovered that in most varieties, the number of leaves at efflorescence was closely expected by the model at higher $\mathrm{N}$ rates. At zero weight unit ha $\mathrm{h}^{-1}$ there are larger errors as most of the predictions were $100 \%$ errors were discovered (leaves of a tree). This shows that the model can predict leaf look and later leaf vary plenty of accurately at higher $\mathrm{N}$ rates than below high $\mathrm{N}$ stress conditions and its impact on LAI.

\section{Grain yield}

Fosu $^{8}$ reiterated that the APSIM model simulated the trend of maize yield fairly well inside the experiments of inorganic $\mathrm{N}$ and $\mathrm{P}$ fertilizer applications. In addition, similar result was reported by 
Miao et al. ${ }^{10}$ The model explained ninety 3 exploit yield variability and performed well at non-zero $\mathrm{N}$ rates, with errors $<10$ the issues. Models, if robust, can play roles not only in data synthesis and prediction, but in addition in heuristics and system vogue. ${ }^{11}$ The models need to be structured as mechanistically as achievable at the extent of the attribute concerned, therefore on embody its biological causes that move to drive system dynamics and to come back up with the nascent consequences at a higher level for the latter two roles. ${ }^{12}$ Cheeseman ${ }^{13}$ showed that victimization equations to stipulate mechanisms for strictly native events permits advanced behavior to emerge at higher levels of organization whereas not separate rules or group action functions. However, no model is completely mechanistic, as results of our understanding that has become eventually restricted with a lowering of the extent of analysis. Therefore, models sometimes facilitated analysis as well as identify data gaps wherever usually mechanistic models are not applied simply because careful modeling at lower levels that will be spared for predicting the attributes at a faraway higher level. ${ }^{14}$ As an associate degree example, the steady-state $\mathrm{C} 3$ chemical change model of Farquhar et al., ${ }^{15}$ is usually thought about as mechanistic; but its lepton transport limitation was supported several assumptions ${ }^{16,17}$ and used only a hyperbolic equation to elucidate the sunshine response of the transport rate, whereas plenty of mechanistic kind for this rate $^{18}$ was largely discarded in addition that whereby necessary is that the got to keep model quality corresponding with the quality and amount of procurable data. Models that square measure fully empirical those square measure hardly used; though they will be used inside explicit contexts ${ }^{19}$ delineated the plant rate of growth just in keeping with a supplying equation as a operate of your time with the aim of visualizing the dynamics of a plant's three-dimensional form. Empirical components square measure, however, still common in several models that square measure mechanistic in their overall structure.

\section{Resistance approach}

A typical transport resistance has been developed as resistance approach to model the partitioning of substrates $(\mathrm{C}$ and $\mathrm{N})$ between roots and shoots that studied by Thornley. ${ }^{20,21}$ In line with the classical Munch's hypothesis, the approach describes the transport rate of $\mathrm{C}$ and $\mathrm{N}$ being proportional to root-shoot substrate concentration gradients divided by a transport resistance, and partitioning may be a results of transport and chemical conversion within the root and shoot. The general frame of this model is mechanistic, however underlying resistance coefficients square measure through empirical observation scaled by structural mass with measuring constants. Another example is that the crop models victimization the conception of sunshine use potency (LUE) to predict crop dry matter production. LUE itself may be a straightforward conception, nonetheless it's sturdy and well depicted. ${ }^{22-24}$ However, several models treat its responses to environmental stresses as: LUE, LUE0 $\mathrm{f}(\mathrm{T}) \mathrm{g}(\mathrm{Ws}) \mathrm{h}(\mathrm{Ns})$, wherever LUE0 is that the baseline value of LUE, and effects of temperature (T), water stress (Ws), and $\mathrm{N}$ stress (Ns) square measure expressed usually by willy-nilly outlined linear section functions. ${ }^{25}$ This was reported that neither individual linear section stress functions ${ }^{26}$ nor the increasing type of the combined stress effect square measure even from a physiological understanding. As for instance, water stress affects growth via each its direct stomatal and non-stomatal regulation of chemical action ${ }^{27}$ and its indirect impact from a modified leaf temperature, increasing forms square measure normally wont to quantify the interactions of environmental factors on physiological parameters. ${ }^{20,21}$ Murthy ${ }^{1}$ gave the basic principle proof that an increasing model are often the end in a wrong direction of interaction between 2 concerned factors (Temperature and $\mathrm{CO}_{2}$ ) on the attribute underneath study of quantum potency of leaf chemical action. This sort of model error will cause unreliable predictions of the impact of global climate change on crop yields. It's troublesome to model all plant processes with an identical mechanistic details. The term 'phenomenological modeling' has been used because the intermediate approach between completely empirical and mechanistic modeling. ${ }^{28}$ This exposes the practicability of avoiding empirical relationships, victimization physiological observations associate example is a way to establish the connection between LAI (L) and total quantity of $\mathrm{N}$ in leaves of a full cover $(\mathrm{N})$. One will draw associate empirical $\mathrm{L}-\mathrm{N}$ relationship from curve-fitting experimental measurements of those 2 variables. One drawback of this curve-fitting is that coefficients of the obtained relationship might don't have any biological which means. It's been established, either through an experiment or on theoretical paper, that:

i. leaf $\mathrm{N}$ at varied heights of the cover ordinarily follows associate exponential profile; Field, ${ }^{29}$ Bertheloot et al. ${ }^{30}$

ii. There's a base price of leaf $\mathrm{N}, \mathrm{nb}$ at or below that the leaf chemical process rate is zero. ${ }^{26}$ Victimization these 2 observations, Yin et al., ${ }^{31}$ given associate $\mathrm{L}-\mathrm{N}$ relationship, wherever $\mathrm{k}$ is that the extinction constant of leaf $\mathrm{N}$ within the cover.

Curve-fitting equation (1) can end in a lot of biologically purposeful parameters $(\mathrm{k}$ and $\mathrm{nb})$ for a completely adult covered canopy that's a cover wherever the $\mathrm{N}$ content of bottom leaves is as low as nb. Any leaf space on the far side the worth given by Equation (1) is meant to senesce; thus Equation (1) engendered a biologically coherent formula to predict leaf senescence, ${ }^{31}$ thereby avoiding empirical stage-dependent leaf turnover coefficients as usually employed in several models. ${ }^{20,21,32}$ This formula will predict associate accelerated leaf senescence of plants adult underneath elevated greenhouse gas conditions as usually determined through an experiment, ${ }^{33-35}$ considering the conception of $\mathrm{C}$ and $\mathrm{N}$ interaction on senescence. ${ }^{36}$

\section{Irrigation water management}

Applied technology to irrigation systems is that the suitable technique to produce property to agricultural production, considering the rational use of the on the market water as a central variable. ${ }^{37}$ The optimum management of accessible surface and submarine water resources, with relevancy quantity and quality, is urgently needed apparent of the increasing demands, restricted resources and soil salinization. ${ }^{38} \mathrm{New}$ technologies and improvement of on-farm water management area unit essential to resolve these issues. ${ }^{39,40}$ Then, one among the accessible technologies inside the gift, ar the selection support systems (DSS), which can be understood as a technological tool to assist the selection making methodology for a selected purpose. A DSS is academic degree interactive machine system that involves the formulation and integration of three main parts, associate info base, academic degree administrator model and a graphical computer virus, and should incorporate the selection makers' own insights a giant improve to the DSS. An internet dynamic decision network was developed to help farm water management in surface irrigation. The web DDSS was supported the formulation and integration of three main components, a dynamic-relational content, associate administrator model Associate in Nursing a graphical program. The DDSS permits routines of making by mental 
acts, edition and addition of on-line data additionally, the system provides to decision makers information in real time to support each, irrigation systems designs and acceptable water management criteria. the web network (INNOVA RIEGO) was applied in Associate in Nursing orange plantation beneath furrow irrigation to measure the particular irrigation management carried on inside the plantation, and determinate every, the suitable water management factors and conjointly the severally irrigation efficiencies of the assembly system. The analysis of the actual water management criteria, sometimes applied by the user, reached lows values of each along with application and total distribution efficiencies of $58.65 \%$ and $61.0 \%$, severally, subsiding as a result a management issue standing equals to "Less than Good" and mistreatment INNOVA RIEGO, these values were improved up to values of ninety $5.89 \%$ for application efficiency and ninety $4.61 \%$ for total distribution efficiency, accomplishing associate "Excellent" management factors standing, taking the furrow discharge, decrease discharge, cut of some time and furrow length as decision support variables. The results achieved, exposed that the user was able to improve on-farm water management, reaching property results, reducing significantly the quantities of percolation and surface runoff, and increasing the irrigation efficiencies. Consequently, this (INNOVA RIEGO) could also be established as a method tool which would assists adequately the selection making methodology, up the efficiency of water management, supporting the property of the farm, and providing flexibility to the agricultural activity what is more as correct data for the management of the on the market water resource.

\section{Conclusion}

Statistical tools indicated that analysis of the APSIM model in full view its credible performance in predicting growth and productivity per unit space of the crops like sorghum, maize and wheat. Hence, agricultural production system machine model (APSIM) is used for higher deciding in choice of acceptable genotypes and management alternatives for agricultural property to work out credibility for APSIM model and to counsel those for native use, careful standardization and validation unit of mensuration needed. Recent studies have shown that combining physiological modeling and genetic mapping (molecular genetics) into a QTL (gene)-based modeling can be powerful to resolve troublesome environment-dependent traits on a genetic basis. Thereto finish, sturdy physiological models that is ready to manifest every genetic and environmental management of crop phenotypes. Although current crop models, partially supported decades-long use of the system dynamics methodology, are thought of by several to be matured system enough for various agricultural applications, they still have to be compelled to be compelled to be upgraded to model genotype-phenotype relationships. Uses of physiological understanding and mathematical tools will overcome the apparent empiricism of the various current crop models. Any progress amongst the realm, the opportunities unit of mensuration be developed a 'crop systems biology' model visible of the wealthy history in natural science and together the arrival of the '-omics' unit of mensuration created public. The 'crop systems biology' model have to be compelled to be compelled to be thought of as photosynthesis-driven adjustment to environmental changes for a way higher understanding some basic processes, this may be achieved by quantifying the imbalance between light-weight energy offer and use in action, and its resultant communication transduction among the short term that is ready to own an impression on leaf morphology among the long run. The system is to be characterized and model factortic variations in property of plant adjustment and victimization data from QTL to gene network analysis unit of mensuration to be applied. The genetic variation among the property of plant adjustment, this information of natural science pathways and phenomenon, and together the magnificence of varied energy-utilizing and dissipating mechanisms have to be compelled to be compelled to administer excellent opportunities to analysis and modeling on crop yields.

\section{Acknowledgements}

The author acknowledges the assistance of water management team of BCKV (State Agricultural University, West Bengal during his tenure as Chief Scientist (2003-2012). The participatory approach of water management technology adoption is only the way to achieve the goal of food security and in the way of sustainable agriculture in the country.

\section{Conflict of interest}

There is no conflict of interest on publishing the article.

\section{References}

1. Murthy VRK. Basic Principles of Agricultural Meteorology. India: Book Syndicate Publishers; 2002.

2. Tsuji GY, Uehara G, Balas S. DSSAT: a decision support system for agrotechnology transfer. Understanding Options for Agricultural Production. 1994:157-177.

3. Whisler FD, Adcock B, Baker DN, et al. Crop models in agronomic systems. Adv Agron. 1986;40:141-208

4. Monteith JL. The quest for balance in crop modelling. Agron J. 1996;88:695-697.

5. Hoogenboom GJ, White JW, Messina CD. From genome to crop: integration through simulation modelling. Field Crop Res. 2004;90(1):145-150.

6. Bouman BA, Van Keulen MH, Van Laar HH. Final Technical Report Calibration and inter-comparison of climate, crop and economic models and assess their strengths and weaknesses in simulating impacts of climate change on agriculture in Eastern Africa. 1996.

7. Jame YW, Cutforth HW. Crop growth models for decision support systems. Can J Plant Sci. 1996;76:9-13.

8. Fosu M, Benedicta Y. Modelling the impact of climate Change on Maize yield Under rain fed Conditions in sub-humid Ghana. United Nations University Institute for Natural Resources in Africa. 2013:38.

9. Gungula DT, Kling JG, Togun AO. CERES-Maize Predictions of Maize Phenology under Nitrogen-Stressed Conditions in Nigeria. Agron J. 2003;95:892-899.

10. Miao Y, Mulla DJ, Batchelor WD, et al. Evaluating Management Zone Optimal Nitrogen Rates with a Crop Growth Model. Agron J. 2006;98(3):545-553.

11. Yin X, Struik PC.Applying modelling experiences from the past to shape crop systems biology: the need to converge crop physiology and functional genomics. New Phytologist. 2008;179(3):629-642.

12. Passioura JB. Accountability, philosophy and plant physiology. Search. 1979;10:347-350.

13. Cheeseman JM. Plant growth modelling without integrating mechanisms. Plant, Cell and Environment. 1993;16(2):137-147.

14. Granier C, Tardieu F. Multi-scale phenotyping of leaf expansion in response to environmental changes: the whole is more than the sum of parts. Plant, Cell and Environment. 2009;32(9):1175-1184. 
15. Farquhar GD, Von Caemmerer S, Berry JA. A biochemical model of photosynthetic $\mathrm{CO}_{2}$ assimilation in leaves of $\mathrm{C} 3$ species. Planta. 1980;149(1):78-90.

16. Yin X, Harbinson J, Struik PC. A model of the generalized stoichiometry of electron transport-limited $\mathrm{C} 3$ photosynthesis: development and applications. In: Laisk A, Nedbal L, Govindjee, editors. Photosynthesis in silico: understanding complexity from molecules to ecosystems. The Netherlands: Springer; 2009. p. 247-273.

17. Yin $\mathrm{X}$, Struik PC. $\mathrm{C}_{3}$ and $\mathrm{C}_{4}$ photosynthesis models: an overview from the perspective of crop modelling. NJAS-Wageningen Journal of Life Sciences. 2009;57(1):27-38.

18. Farquhar GD, Von Caemmerer S. Electron transport limitations in the $\mathrm{CO}_{2}$ assimilation rate of leaves: a model and some observations in Phaseolus vulgaris L. In: Akoyunoglou G, editor. Photosynthesis. regulation of carbon metabolism. Philadelphia, PA: Balaban International Science Services; 19811. p. 63-175.

19. Mundermann L, Erasmus Y, Lane B, et al. Quantitative modeling of Arabidopsis development. Plant Physiology. 2005;139(2):960-968.

20. Thornley JHM. A balanced quantitative model for root:shoot ratios in vegetative plants. Annals of Botany. 1972;36(2):431-441.

21. Thornley JHM. Grassland dynamics: an ecosystem simulation model. UK: CAB International; 1998.

22. Charles Edwards DA. Physiological determinants of crop growth. Sydney: Academic Press; 1982. 161 p.

23. Monteith JL. Validity of the correlation between intercepted radiation and biomass. Agricultural and Forest Meteorology. 1994;68(3-4):213220.

24. Dewar RC. The correlation between plant growth andintercepted radiation: an interpretation in terms of optimal plant nitrogen content Annals of Botany. 1996;78(1):25-136

25. Brisson N, Mary B, Ripoche D. STICS: a generic model for the simulation of crops and their water and nitrogen balance. I. Theory and parameterization applied to wheat and corn. Agronomie. 1998;18(56):311-346

26. Sinclair TR, Horie T. Leaf nitrogen, photosynthesis, and crop radiation use efficiency: a review. Crop Science. 1989;29(1):90-98.

27. Tezara W, Mitchell V, Driscoll SP, et al. Effects of water deficit and its interaction with $\mathrm{CO}_{2}$ supply on the biochemistry and physiology of photosynthesis in sunflower. Journal of Experimental Botany. 2002;53(375):1781-1791
28. Van Oijen M, Levy P. Nitrogen metabolism and plant adaptation to the environment- the scope for process-based modelling. In: Amancio S, Stulen I, editors. Nitrogen acquisition and assimilation in higher plants. Netherlands: Kluwer Publishers; 2004. p. 133-147.

29. Field C. Allocating leaf nitrogen for the maximization of carbon gain: leaf age as a control on the allocation program. Oecologia. 1983;56(23):341-347.

30. Bertheloot J, Martre P, Andrieu B. Dynamics of light and nitrogen distribution during grain filling within wheat canopy. Plant Physiology 2008;148(3):1707-1720.

31. Yin X, Schapendonk AHCM, Kropff MJ, et al. A generic equation for nitrogen-limited leaf area index and its application in crop growth models for predicting leaf senescence. Annals of Botany. 2000;85(5):579-585.

32. Bouman BAM, Kropff MJ, Tuong TP, et al. ORYZA2000: modelling lowland rice. Philippines: IRRI; 2001. 235 p.

33. Kartschall T. Productivity and water use of wheat under free-air $\mathrm{CO}_{2}$ enrichment. Global Change Biology. 1995;1(6):429-442.

34. Kimball BA, Pinter PJ, Garcia RL, et al. Elevated Atmospheric $\mathrm{CO}_{2}$ Improved Sorghum Plant Water Status by Ameliorating the Adverse Effects of Drought. The new pathologist. 2001;152(2):231-248.

35. Zhu C, Zhu J, Zeng Q, et al. Elevated $\mathrm{CO}_{2}$ accelerates flag-leaf senescence in wheat due to ear photosynthesis which causes greater ear nitrogen sink capacity and ear carbon sink limitation. Functional Plant Biology. 2009;36(4):291-299.

36. Paul MJ, Pellny TK. Carbon metabolite feedback regulation of leaf photosynthesis and development. Journal of Experimental Botany. 2003;54(382):539-547.

37. Flores C, Holzapfel E. Dynamic decision system support to assist the suitable water management of an orchard under furrow irrigation. Proc the International Conference Science and Information Technologies for Sustainable Management of Aquatic Ecosystems, 8th International Conference on Hydroinformatics, Concepción. Chile: Universidad de Concepción, Concepción; 2009. 100 p.

38. Flores C, Holzapfel EA, Octavio Lagos. Rivera YD. A Dynamic Decision Support System for Farm Water Management in Surface Irrigation: Model Development and Application. Chilean journal of agricultural research. 2010;70(2): 278-286.

39. Kumar R, Singh J. Regional water management modeling for decision support in irrigated agriculture. J Irrig Drain E. 2003;129:432-439.

40. Chen J, Reynolds JF, Harley PC, et al. Coordination theory of leaf nitrogen distribution in a canopy. Oecologia.1993;93(1):63-69. 